\title{
Novel Hydralazine Schiff Base Derivatives and Their Antimicrobial, Antioxidant and Antiplasmodial Properties
}

\author{
Angelbert F. Awantu1 ${ }^{*}$, Yannick Stephane F. Fongang'2, Godfred A. Ayimele ${ }^{3}$, \\ Edouard A. Nantia 4 , Patrick V. T. Fokou ${ }^{5}$, Fabrice F. Boyom ${ }^{5}$, Celine K. Ngwang 3 , \\ Bruno N. Lenta ${ }^{6}$, Silvère A. Ngouela ${ }^{7}$ \\ ${ }^{1}$ Department of Chemistry, The University of Bamenda, Bambili, Cameroon \\ ${ }^{2}$ Department of Chemistry, University of Maroua, Maroua, Cameroon \\ ${ }^{3}$ Department of Chemistry, University of Buea, Buea, Cameroon \\ ${ }^{4}$ Department of Biochemistry, The University of Bamenda, Bambili, Cameroon \\ ${ }^{5}$ Department of Biochemistry, University of Yaoundé I, Yaoundé, Cameroon \\ ${ }^{6}$ Department of Chemistry, Higher Teachers' Training College, University of Yaoundé I, Yaoundé, Cameroon \\ ${ }^{7}$ Department of Organic Chemistry, Faculty of Science, University of Yaoundé I, Yaoundé, Cameroon \\ Email: ^aawantu@gmail.com
}

How to cite this paper: Awantu, A.F., Fongang, Y.S.F., Ayimele, G.A., Nantia, E.A., Fokou, P.V.T., Boyom, F.F., Ngwang, C.K., Lenta, B.N. and Ngouela, S.A. (2020) Novel Hydralazine Schiff Base Derivatives and Their Antimicrobial, Antioxidant and Antiplasmodial Properties. International Journal of Organic Chemistry, 10, 1-16. https://doi.org/10.4236/ijoc.2020.101001

Received: January 27, 2020

Accepted: March 3, 2020

Published: March 6, 2020

Copyright $\odot 2020$ by author(s) and Scientific Research Publishing Inc. This work is licensed under the Creative Commons Attribution International License (CC BY 4.0).

http://creativecommons.org/licenses/by/4.0/

\begin{abstract}
Two novel Schiff bases, 3-[1-(2-(phthalazin-1-yl)hydrazono)ethyl)-1,3-oxazinane (PHEO) and 2-[(2-(phthalazin-1-yl)hydrazono)methyl]phenol (PHMP), derived from hydralazine hydrochloride, an effective drug against hypertension, were synthesized and characterized by spectroscopic methods, Infrared (IR), Proton Nuclear Magnetic Resonance ( ${ }^{1} \mathrm{H}$ NMR) and Carbon-13 Nuclear Magnetic Resonance $\left({ }^{13} \mathrm{C}\right.$ NMR). PHEO showed low antimicrobial activity against one bacterial strain with MIC value of $250 \mu \mathrm{g} / \mathrm{ml}$ while PHMP showed interesting activity against 4 bacterial strains with MIC of $31.25-250 \mu \mathrm{g} / \mathrm{ml}$ compared to the standard drug, amoxicillin. PHEO and PHMP showed higher reducing activity on ferric ions compared to Vitamin C. On lipid peroxidation, PHEO showed higher inhibition while PHMP showed lower inhibition compared to Vitamin C. Both compounds presented lower stimulating effect and lower catalase activity compared to the standard Vitamin C. PHEO and PHMP showed less than $80 \%$ inhibition in the preliminary antiplasmodial assay and so were not considered for the dose-response studies.
\end{abstract}

\section{Keywords}

Hydralazine Hydrochloride, Schiff Bases, Antimicrobial, Anti-Oxidant, Anti-Plasmodial Activities 


\section{Introduction}

Health problems have been a source of sadness and pain to humanity and research in the domain of health has afforded a great variety of therapeutics to fight against a wide range of diseases and ailments. Despite this effort and many others, some drugs have become ineffective as the micro organism develops resistance when the usage is recurrent, reason why illnesses like malaria, bacterial and yeast infections, gastrointestinal disorders, diarrhoea, dysentery, cholera, as well as chronic degenerative diseases like cancer, continue to inflict suffering in developing countries, Africa and the world. There is therefore urgent need to discover new drugs.

Condensation between primary amines and carbonyl compounds affords Schiff bases. The imine $(-\mathrm{C}=\mathrm{N}-)$ functional group is a versatile pharmacophore for the design and development of biologically active leads. Schiff bases constitute an important class of organic compounds that show a wide variety of applications in many fields including the pharmaceutical and medicinal fields because of the wide range of biological activities they portray including anti-inflammatory [1] [2] [3] [4], antimicrobial [5] [6], antitubercular [7], antioxidant [8], anthelmintic [9], analgesic [2] [3] [4] [10] and anticonvulsant [11] activities among others. Apart from their pharmaceutical and medicinal importance, Schiff bases are widely used as catalysts, dyes, stabilizers in polymer formulations, pigments and corrosion inhibitory agents [12].

The growing resistance of infectious microorganisms to therapeutics is a serious concern and represents a health threat in both developed and developing world [13]. Introduction of new classes of antimicrobial drugs is desperately needed to hamper the tendency of drugs to quickly develop drug-resistant pathogens [13]. Therefore, drug discovery efforts will facilitate the identification of novel antimicrobial compounds and new drug combinations will facilitate the development of better dosing regimens and novel strategies to manage drug resistance and prevent the dissemination of resistant bacteria [14]. In Cameroon, infectious diseases such as malaria and bacterial infections are amongst the most commonly notified diseases and largest cause of mortality [15]. Malaria continues to be a major cause of childhood mortality and was responsible for an estimated 303,000 (165,000 - 450,000) deaths in children under 5 years old in 2015. The majority is caused by the Plasmodium falciparum infections. However, the $60 \%$ reduction observed in mortality since 2000 is heavily associated to the widespread deployment of effective control measures such as Artemisinin-based Combination Therapies (ACTs). The recent emergence and spread of Plasmodium falciparum parasites resistant to ACTs, worsened by the spread of insecticide resistance hindered the elimination of malaria [16] [17] [18].

An antioxidant is any molecule that delays, prevents or removes oxidative damage to target cells. Oxidative damage or oxidative stress produces free radicals which are dangerous to the body. Reactive oxygen species (ROS) is a term which encompasses all highly reactive molecules including free radicals like hy- 
droxyl radical, superoxide anion radical, hydrogen peroxides, singlet oxygen, nitric acid radical and various peroxides [19]. When oxidative forces exceed the antioxidant systems, the cell is subjected to oxidative stress [19]. Oxidative stress is among the major causative factors in induction of many chronic and degenerative diseases including atherosclerosis, ischemic heart disease, aging, diabetes mellitus, cancer, immunosuppression, neurodegenerative diseases, male infertility, infectious diseases and others [20]. Therefore, development of new antimalarial, antibacterial and antioxidant chemotypes is an urgent priority. Our objective in this study is to synthesize new hydralazine-derived Schiff bases and to evaluate them for their antiplasmodial, antibacterial and antioxidant activity in vitro.

\section{Experimental}

\subsection{Materials}

Hydralazine hydrochloride, 4-acetylmorpholine, 2-hydroxybenzaldehyde and other solvents were purchased from commercial sources and used without further purification. All chemicals used were of reagent grade. Methanol was used as solvent all through the synthesis. Glass apparatus with standard interchangeable joint were used after being washed with concentrated sulphuric acid, distilled water and methanol. All the synthesis was carried out in a $250 \mathrm{~mL}$ round-bottomed flask fitted with a quick Liebig condenser where it involved refluxing. All reactions were performed on a hot plate equipped with a magnetic stirrer. Elemental analysis was performed on a VARIO EL (Heraeus) analyzer. IR spectra were obtained from a Perkin-Elmer spectrum 100-FT-IR spectrometer. ${ }^{1} \mathrm{H}$-NMR spectra were obtained on a Varian unity plus $400 \mathrm{MHz}$ instrument. ${ }^{13} \mathrm{C}-\mathrm{NMR}$ spectra were recorded on a Bruker AV $100 \mathrm{MHz}$ instrument.

\subsection{Synthesis of 3-[1-(2-(Phthalazin-1-yl)Hydrazono)Ethyl)- 1,3-0xazinane (PHE0)}

The ligand was prepared by the condensation reaction between hydralazine hydrochloride and 4-Acetylmorpholine. ( $3 \mathrm{mmol}, 0.6 \mathrm{~g}$ ) of hydralazine hydrochloride and sodium acetate (buffering agent) $(3 \mathrm{mmol}, 0.4 \mathrm{~g}$ ) was dissolved in 20 $\mathrm{mL}$ of ethanol, and ( $3 \mathrm{mmol}, 0.4 \mathrm{~g}$ ) of 4-Acetylmorpholine was also measured. The two solutions were transferred into a $250 \mathrm{~mL}$ round bottom flask and the mixture was refluxed for three hours while stirring at a temperature of $70^{\circ} \mathrm{C}$ and allowed to cool overnight. The yellow precipitate obtained (PHEO) was separated by filtration, washed with ethanol and allowed to air dry giving a yield of $50 \%$. The filtrate was sealed using paraffin in a vial and kept for further crystalization by slow evaporation to improve on the yield. The synthetic route for PHEO is shown in Scheme 1.

IR $\left(\mathrm{KBr}, \mathrm{cm}^{-1}\right): v 3862,3501,1271,1664,1611,970 .{ }^{1} \mathrm{H}$ NMR (DMSO-d ${ }_{6}, 500$ MHz): 8.85 (s, 1H, N-H), 8.10 (dd, $1 \mathrm{H}, \mathrm{C}-\mathrm{H}$ of benzene ring), 2.45 (s, 3H, H-8'), 2.29 (t, 4H, H-3', H-4'), 2.60 (t, 4H, H-6', H-7') ppm. ${ }^{13} \mathrm{C}$ NMR (DMSO-d $\mathrm{d}_{6}, 125$ $\mathrm{MHz})$ : 151.6 (C-1'), 135.9 (C-1), 134.2 (C-4) ppm. 


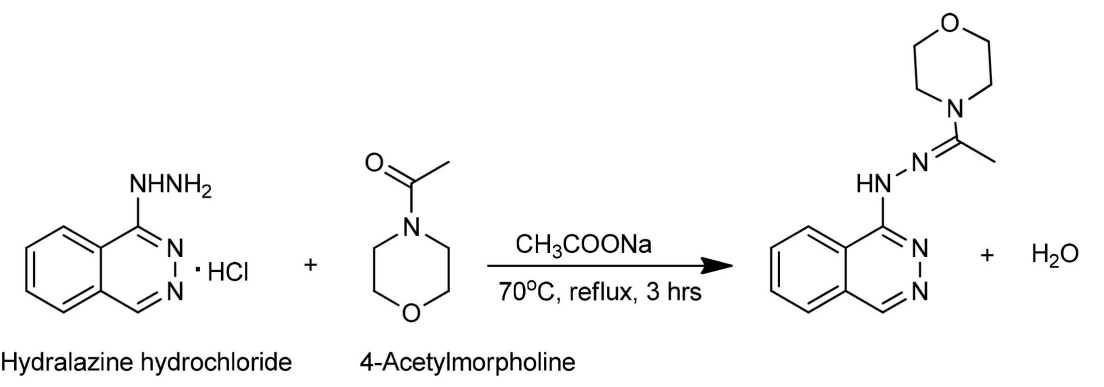

Scheme 1. Synthesis of PHEO.

\subsection{Synthesis of}

\section{2-[(2-(Phthalazin-1-yl)Hydrazono)Methyl]Phenol (PHMP)}

A $(1.0 \mathrm{mmol}, 0.201 \mathrm{~g})$ of hydralazine hydrochloride and sodium acetate (buffering agent) ( $1.0 \mathrm{mmol}, 0.137 \mathrm{~g}$ ) was dissolved in $15 \mathrm{~mL}$ of ethanol and mixed with $0.104 \mathrm{~mL}$ of 2-hydroxybenzaldehyde. The solution was transferred into a $100 \mathrm{~mL}$ round bottom flask and then refluxed for three hours while stirring at a temperature of about $70^{\circ} \mathrm{C}$ to $75^{\circ} \mathrm{C}$ and allowed to cool overnight. The yellow precipitate (PHMP) was separated by filtration, washed with ethanol and allowed to air dry (yield $=76.05 \%$ ). The filtrate was sealed using paraffin in a vial and kept for further crystalization by slow evaporation to improve on the yield. Scheme 2 shows the synthetic route for PHMP.

IR $\left(\mathrm{KBr}, \mathrm{cm}^{-1}\right): v 3400,3100.1,1267.9,1607.4,960.9 .{ }^{1} \mathrm{H}$ NMR $\left(\mathrm{DMSO}_{-} \mathrm{d}_{6}, 500\right.$ MHz): 12.11 (s, 1H, OH), 10.30 (s, 1H, N-H), 8.69 (s, 1H, H-1'), 6.90 and 8.33 (benzene hydrogens of the hydralazine moiety) ppm. ${ }^{13} \mathrm{C}$ NMR (DMSO- $\mathrm{d}_{6}, 125$ MHz): 157.0 (C-1), 154.0 (C-3'), 147.0 (C-1') ppm.

\subsection{Organisms and Growth Conditions}

Microorganisms were obtained from the culture collections of the Antimicrobial and biocontrol Agents Unit at the Department of Biochemistry, University of Yaounde 1, Cameroon. Organisms were as follows: Streptococcus pneumoniae (Klein) Chester, ATCC49619, Staphylococcus aureus BAA 917, Staphylococcus aureus subsp. aureus Rosenbach, ATCC 43300, Staphylococcus aureus NR45003, Staphylococcus aureus NR46003, Staphylococcus aureus CP7625, Shigella flexineri NR518, Salmonella enterica subsp. enterica serovar AnatumNR4294, Salmonella enterica subsp. enterica serovar Muenchen NR4311, Salmonella enterica subsp. enterica, strain A36 is serovar TyphimuriumNR-13555, Pseudomonas aeruginosa NMC592, Klebsiella pneumoniae subsp. pneumoniae (Schroeter) Trevisan ATCC 13883, Klebsiella pneumoniae subsp. pneumoniae (Schroeter) Trevisan ATCC 700603, Klebsiella pneumonae NR41916, Escherishia coli ATCC25922, Escherishia coli ATCC35218, Enterococcus feacalis ATCC51219, Staphylococcus aureus NR46374, and Hemophyllus influenza ATCC49247. Organisms were maintained on Muller Hinton agar (MHA) (Oxoid). at $37^{\circ} \mathrm{C}$. Inocula were prepared by diluting overnight cultures in saline to $0.5 \mathrm{McFarland}$, approximately $10^{8} \mathrm{cfu} \cdot \mathrm{ml}^{-1}$. These suspensions were further diluted with medium as required. 


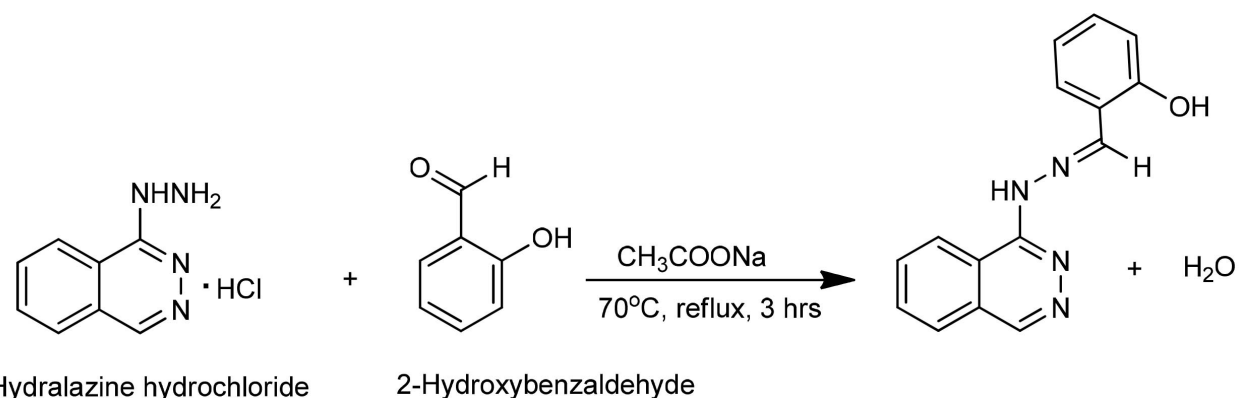

Hydralazine hydrochloride

2-Hydroxybenzaldehyde

Scheme 2. Synthesis of PHMP.

Drug susceptibility Testing Procedure

\section{Stock solution preparation}

Stock solution of each sample was prepared at $100 \mathrm{mg} / \mathrm{mL}$ in DMSO.

\subsection{Antimicrobial Assays}

For the estimation of the antimicrobial activities of the plant extracts, a broth dilution method was employed for minimum inhibitory contraction (MIC) following the Clinical and Laboratory Standards Institute (CLSI) guidelines M07-A10. Each compound was tested in duplicate for MIC determination. More specifically, $50 \mu \mathrm{L}$ of Mueller Hinton broth (MHB) were introduced in a 96-well microplate respectively. $50 \mu \mathrm{L}$ of compound were added to wells of the first line. A serial twofold dilution was made by transferring $50 \mu \mathrm{L}$ of the mixture of the first wells to the next one up to the last, final concentrations varying from 250 to $7.81 \mu \mathrm{g} / \mathrm{mL}$. Then, $50 \mu \mathrm{L}$ of an inoculum of $1 \times 10^{6}$ cells $/ \mathrm{mL}$ were introduced in all the wells except those of the sterility control. The final concentration of DMSO was $<1 \%$. Each plate also contained a positive control, Amoxicillin, a negative control and a blank. Plates were incubated during 24 hours. The lowest concentration of compound that inhibited the visible growth of a microorganism was defined as minimum inhibitory concentration (MIC).

\subsection{Antioxidant Assay}

\subsubsection{Organ Homogenates}

A 2.5 month old male Wistar albino rat of $150 \mathrm{~g}$ was obtained from the Biochemistry animal house of the Faculty of Science of the University of Bamenda. They were handled according to ethical guidelines of the Cameroon National Veterinary Laboratory and were given food and water ad libitum. After sacrifice, the liver and testes were excised out, weighed and used to prepare $20 \%(\mathrm{~W} / \mathrm{V})$ homogenates using phosphate buffer ( $\mathrm{pH}$ 7.4, $50 \mathrm{mM}$ ).

\subsubsection{Chemicals}

Ascorbic acid and Thiobarbituric, trichloroacetic acids were gotten from Griffin and George (Wembly Middlesex, England). Methanol was purchased from LobaChemiePvt. Ltd. 107, Woodehouse (Mumbai, India). Other chemicals were of high quality grade. 


\subsubsection{Evaluation of the Antioxidant Reducing Power}

The antioxidant reducing power of the synthesized compounds PHEO and PHMP was evaluated using the method as described by Kamtekar and collaborators in 2014 [21]. The standard ascorbic acid or synthesized compounds (50, $100,150,200,250$ and $300 \mu \mathrm{g} / \mathrm{mL}$ ) was introduced in the tube, then $0.4 \mathrm{~mL}$ of phosphate buffer $(\mathrm{pH} 6.6,0.2 \mathrm{M})$ and $0.4 \mathrm{~mL}$ of $1 \% \mathrm{KFe}(\mathrm{CN})_{6}$ were successively added. After homogenization, the mixture was incubated at $50^{\circ} \mathrm{C}$ for $20 \mathrm{~min}$, then cooled, and centrifuged ( $\left.3500 \mathrm{rpm}, 10 \mathrm{~min}, 25^{\circ} \mathrm{C}\right)$. To $1 \mathrm{~mL}$ of supernatant was added $1 \mathrm{~mL}$ of $10 \%$ TCA, $1 \mathrm{~mL}$ of distilled water and $0.2 \mathrm{~mL}$ of $0.1 \% \mathrm{FeCl}_{3}$. After homogenization, the absorbance was measured at $593 \mathrm{~nm}$ using a UV-Vis spectrophotometer.

\subsubsection{Inhibition of Lipid Peroxidation}

A volume $(0.8 \mathrm{~mL})$ of phosphate buffer $(\mathrm{pH} 7.4,50 \mathrm{mM})$ and $0.1 \mathrm{~mL}$ of liver or testis homogenate were added to standard ascorbic acid or synthesized compounds, PHEO and PHMP (50, 100, 150, 200, 250 and $300 \mu \mathrm{g} / \mathrm{mL})$, followed by $0.1 \mathrm{~mL}$ of $\mathrm{Fe}_{2}\left(\mathrm{SO}_{4}\right)_{2}$. After homogenization, the mixture was incubated at $37^{\circ} \mathrm{C}$ for $15 \mathrm{~min}$, then $1 \mathrm{~mL}$ of $20 \%$ TCA and $1 \mathrm{~mL}$ of $0.67 \%$ TBA, were added. The mixture was incubated at $90^{\circ} \mathrm{C}$ for $10 \mathrm{~min}$, cooled and centrifuged (3000 rpm, 15 $\min , 4^{\circ} \mathrm{C}$ ). The supernatant was collected and optical density read at $530 \mathrm{~nm}$ [22] and percentage inhibition (\%I) of the standard and the synthesized compounds, PHEO and PHMP computed.

\subsubsection{Catalase Activity}

Ascorbic acid or the synthesized compounds, PHEO and PHMP (50, 100, 150, 200,250 and $300 \mu \mathrm{g} / \mathrm{mL}$ ) were introduced into test tubes containing $0.4 \mathrm{~mL}$ of $9 \% \mathrm{H}_{2} \mathrm{O}_{2}$ and $2.3 \mathrm{~mL}$ of phosphate buffer $(\mathrm{pH} 7.2,0.1 \mathrm{M})$ and $0.4 \mathrm{~mL}$ of the liver or testis homogenate were added. The absorbance was recorded at $240 \mathrm{~nm}$ using a UV-Vis spectrophotometer at 30, 60 and 90 seconds. Catalase activity was expressed as IU/mg protein [23].

\subsubsection{Statistical Analyses}

For ferric reducing power and lipid peroxidation, the fifty percent efficient $\left(\mathrm{EC}_{50}\right)$ and inhibitory $\left(\mathrm{IC}_{50}\right)$ concentration of the tested compound were determined. Differences between treatments were assessed by one factor ANOVA followed by the Student-Newman-Keulstest, and $\mathrm{P}$ values less than 0.05 were considered statistically significant. All analyses were performed using Graphpad Instat software Version 3.0.

\subsection{Antiplasmodial Assay}

\section{SYBR Green I Based Fluorescence Assay}

Drug sensitivity assay was carried out in 96-well microtitration plates using SYBR green I based fluorescence assay. Sorbitol-synchronized ring stage parasites, Plasmodium falciparum Dd2 (haematocrit: 3\%, parasitaemia: 0.5\%, $90 \mu \mathrm{l}$ ) under normal culture conditions were incubated in the presence of prediluted 
extracts and reference drug. The final concentration in the test plate was range from 0.781 to $100 \mu \mathrm{g} / \mathrm{mL}$ for extract and 0.0078 to $1 \mu \mathrm{M}$ for artemisinin and chloroquine, in the total volume of $100 \mu \mathrm{L}$ of culture. After $72 \mathrm{~h}$ of incubation, SYBR Green I was added and the fluorescence was measured using a Fluoroskan Ascent multi-well plate reader with excitation and emission at 485 and $538 \mathrm{~nm}$, respectively. The fluorescence counts were plotted against the logarithm of sample concentration and the $50 \%$ inhibitory concentration $\left(\mathrm{IC}_{50}\right)$ was determined by analysis of dose-response curves using GraphPad Prism 5. Experiments were done in duplicate. Cut off point for antiplasmodial activity of synthesized compounds is as follows: Highly active $\left(\mathrm{IC}_{50} \leq 5 \mu \mathrm{g} / \mathrm{mL}\right)$, promisingly active $\left(5<\mathrm{IC}_{50}\right.$ $\leq 10 \mu \mathrm{g} / \mathrm{mL})$, good activity $10<\mathrm{IC}_{50} \leq 20 \mu \mathrm{g} / \mathrm{mL}$, moderately active $\left(20<\mathrm{IC}_{50} \leq\right.$ $40 \mu \mathrm{g} / \mathrm{mL})$, marginally active $\left(40<\mathrm{IC}_{50} \leq 70 \mu \mathrm{g} / \mathrm{mL}\right)$, poorly active $\left(70<\mathrm{IC}_{50} \leq\right.$ $100 \mu \mathrm{g} / \mathrm{mL})[24]$.

\section{Results and Discussion}

The condensation reaction between hydralazine hydrochloride and 4-acetylmorpholine afforded PHEO (Figure 1) and that between hydralazine hydrochloride and 2-hydroxybenzaldehyde afforded PHMP (Figure 2).

\subsection{Infrared Spectra}

The IR spectrum of the PHMP (Figure 3) recorded in the $4000-400 \mathrm{~cm}^{-1}$ region displayed strong bands at $3400 \mathrm{~cm}^{-1}$ and $3100.1 \mathrm{~cm}^{-1}$ corresponding to the $\mathrm{O}-\mathrm{H}$ and the $\mathrm{N}-\mathrm{H}$ stretching vibrations respectively [25]. A sharp band was seen at<smiles>[3H]C(Br)=NNc1nncc2cc(Br)ccc12</smiles>

Figure 1. Structural features of PHEO.<smiles>[3H]/C(=N\Nc1nncc2cc(I)ccc12)c1c[se][14cH]c1O</smiles>

Figure 2. Structural features of PHMP. 


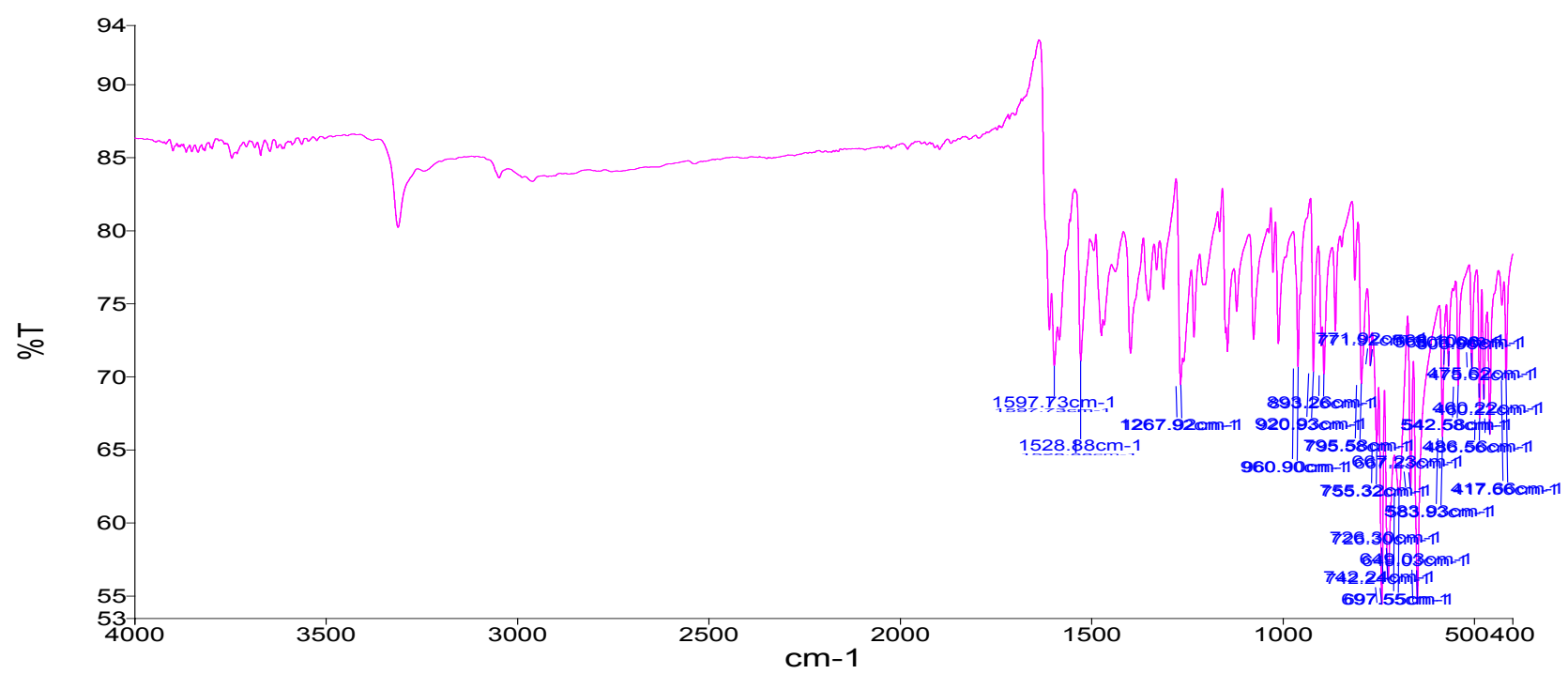

Figure 3. Infrared spectrum of PHMP.

$1267.9 \mathrm{~cm}^{-1}$ corresponding to the $\mathrm{C}-\mathrm{O}$ stretch. Other strong bands were observed at $1607.4 \mathrm{~cm}^{-1}$ corresponding to the $\mathrm{C}=\mathrm{N}$ stretch [26] and at $960.9 \mathrm{~cm}^{-1}$ attributed to the N-N stretch. This brought in to evidence the presence of these functional groups in PHMP.

The IR spectrum of the PHEO (Figure 4) recorded in the $4000-400 \mathrm{~cm}^{-1}$ region showed a band at $3862 \mathrm{~cm}^{-1}$ for the residual $\mathrm{H}_{2} \mathrm{O}$ molecule [25]. Also, sharp bands at $3501 \mathrm{~cm}^{-1}$ and $1664 \mathrm{~cm}^{-1}$ corresponding to the $\mathrm{N}-\mathrm{H}$ stretch and the azomethine $\mathrm{C}=\mathrm{N}$ respectively. Other sharp bands were observed at $1271 \mathrm{~cm}^{-1}$ and $970 \mathrm{~cm}^{-1}$ attributed to the $\mathrm{C}-\mathrm{O}$ stretch and $\mathrm{N}-\mathrm{N}$ stretch respectively. The band observed at $1611 \mathrm{~cm}^{-1}$ was that of the $\mathrm{C}=\mathrm{N}$ stretch [26]. The very intense band at $1611 \mathrm{~cm}^{-1}$ is attributed to the $\mathrm{C}=\mathrm{C}$ vibration [25].

\section{2. ${ }^{1} \mathrm{H}$ NMR Spectra}

The proton NMR spectrum of PHMP (Figure 5) was recorded in deuterated DMSO as the solvent. The signal at $12.11 \mathrm{ppm}(1 \mathrm{H}, \mathrm{s})$ is attributed to the $\mathrm{O}-\mathrm{H}$ while that at $10.30 \mathrm{ppm}(1 \mathrm{H}, \mathrm{s})$ is attributed to the $\mathrm{N}-\mathrm{H}$ and is highly deshielded because of its tautomeric nature. A signal observed at $8.69 \mathrm{ppm}(1 \mathrm{H}$, s) was attributed to the methyne $(-\mathrm{N}=\mathrm{C}-\mathrm{H})$ proton at carbon 1 '. The group of signals between $6.90 \mathrm{ppm}$ and $8.33 \mathrm{ppm}$ has been attributed to the benzene protons of the hydralazine moiety. Figure 5 shows the ${ }^{1} \mathrm{H}$ NMR spectrum of the PHMP.

The proton NMR spectrum of PHEO (Figure 6) was recorded in deuterated methanol $\left(\mathrm{CD}_{3} \mathrm{OD}\right)$ as the solvent. The signal at $8.85 \mathrm{ppm}(1 \mathrm{H}, \mathrm{s})$ is attributed to the N-H of the hydralazine; deshielded because of its tautomeric nature, while that at $8.10 \mathrm{ppm}(1 \mathrm{H}, \mathrm{dd})$ is attributed to the $\mathrm{C}-\mathrm{H}$ of the benzene ring. The signal at $2.45 \mathrm{ppm}(3 \mathrm{H}, \mathrm{s})$ is attributed to the methyl group while those at $2.29 \mathrm{ppm}$ $(4 \mathrm{H}, \mathrm{t})$ and $2.60 \mathrm{ppm}(4 \mathrm{H}, \mathrm{t})$ are attributed to the two groups of methylene protons of the morpholine moiety. Figure 6 shows the ${ }^{1} \mathrm{H}$ NMR spectrum of the PHEO. 


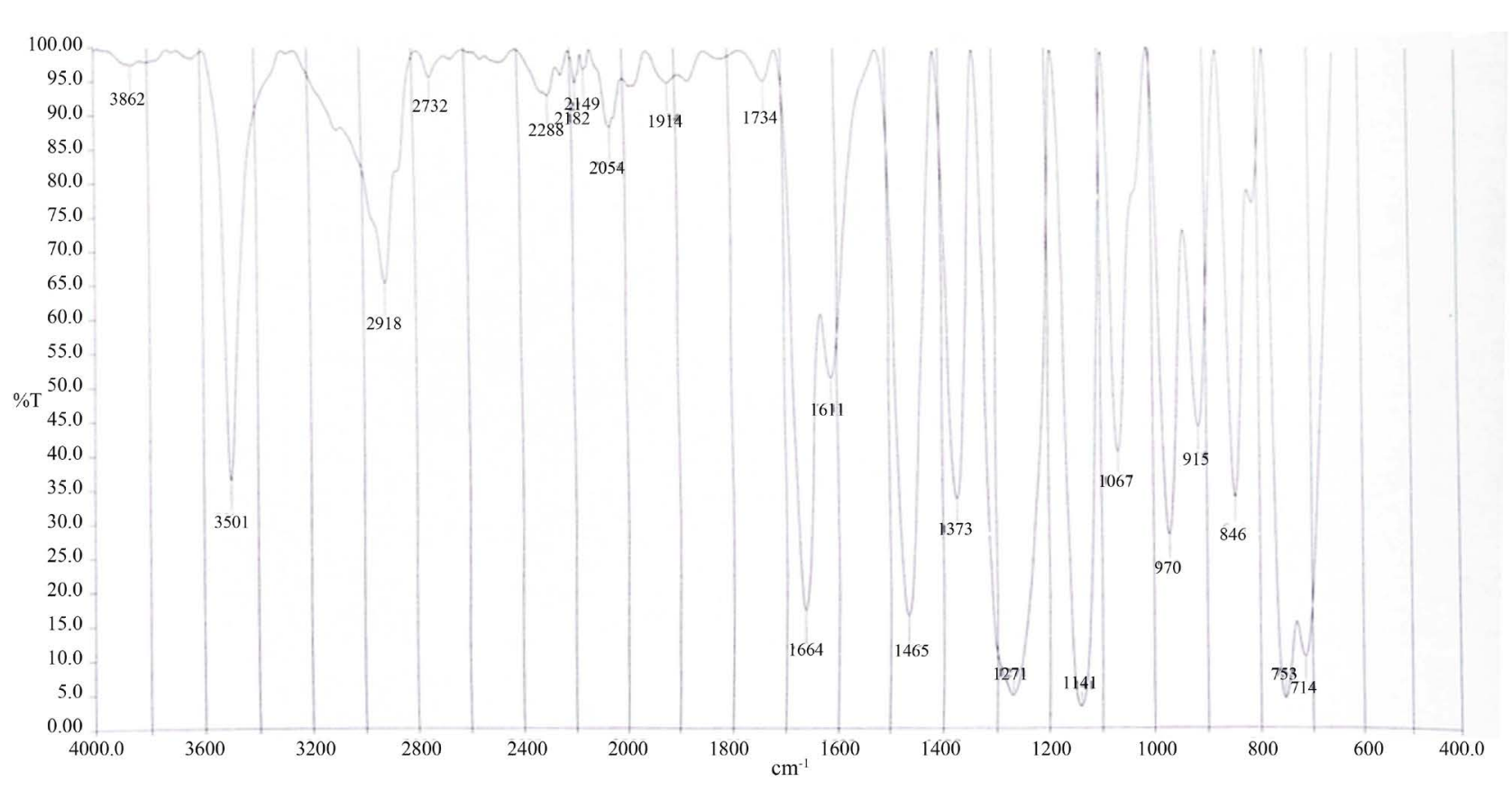

Figure 4. Infrared spectrum of PHEO.

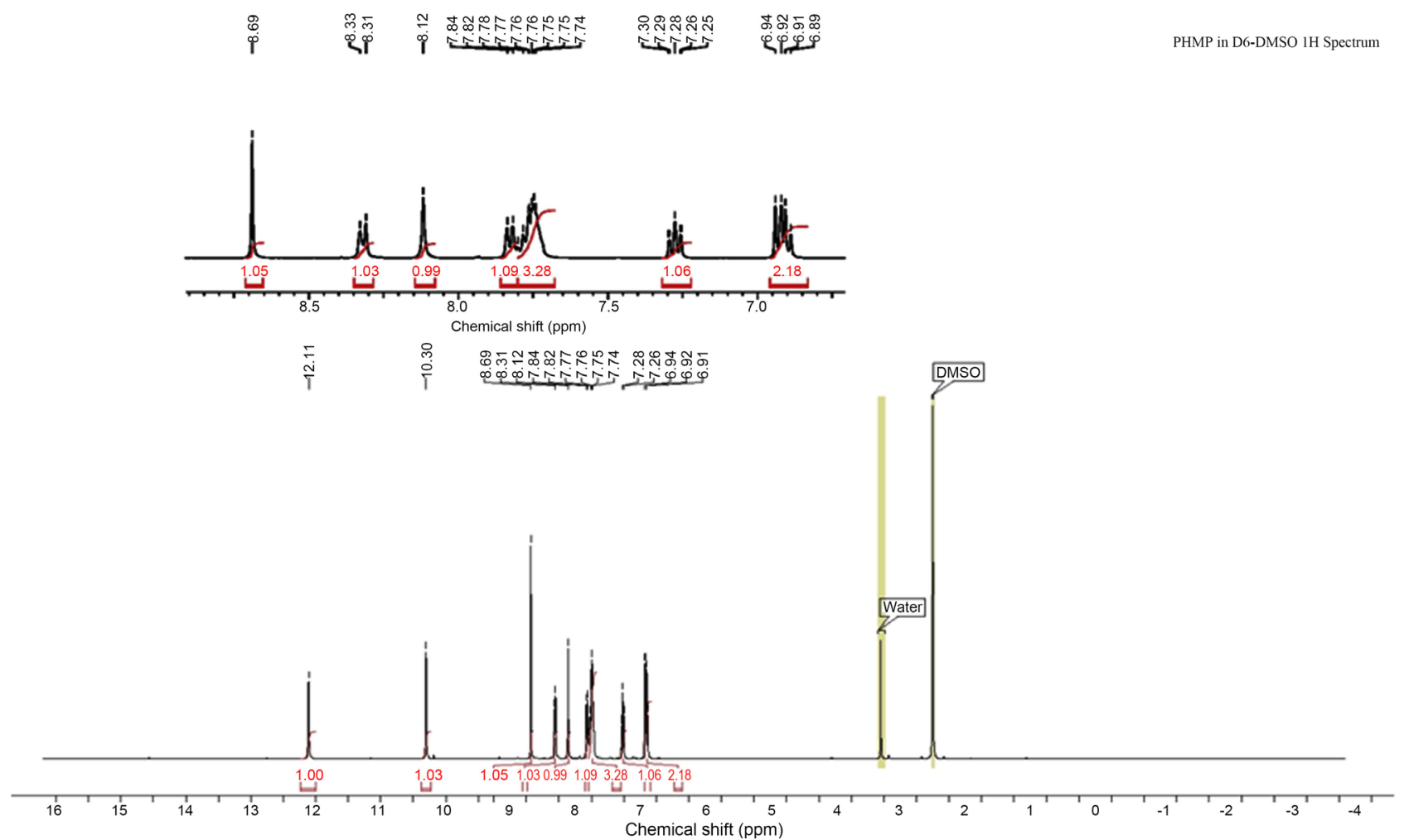

Figure 5. ${ }^{1} \mathrm{H}-\mathrm{NMR}$ spectrum of PHMP.

The ${ }^{13} \mathrm{C}$ NMR spectrum of PHMP (Figure 7) was recorded in deuterated DMSO as the solvent. It displayed 15 signals between $116.0 \mathrm{ppm}$ and $157.0 \mathrm{ppm}$. The signals at 157.0, 154.0 and 147.0 were respectively attributed to carbons 1,3 ' and 1 '. 


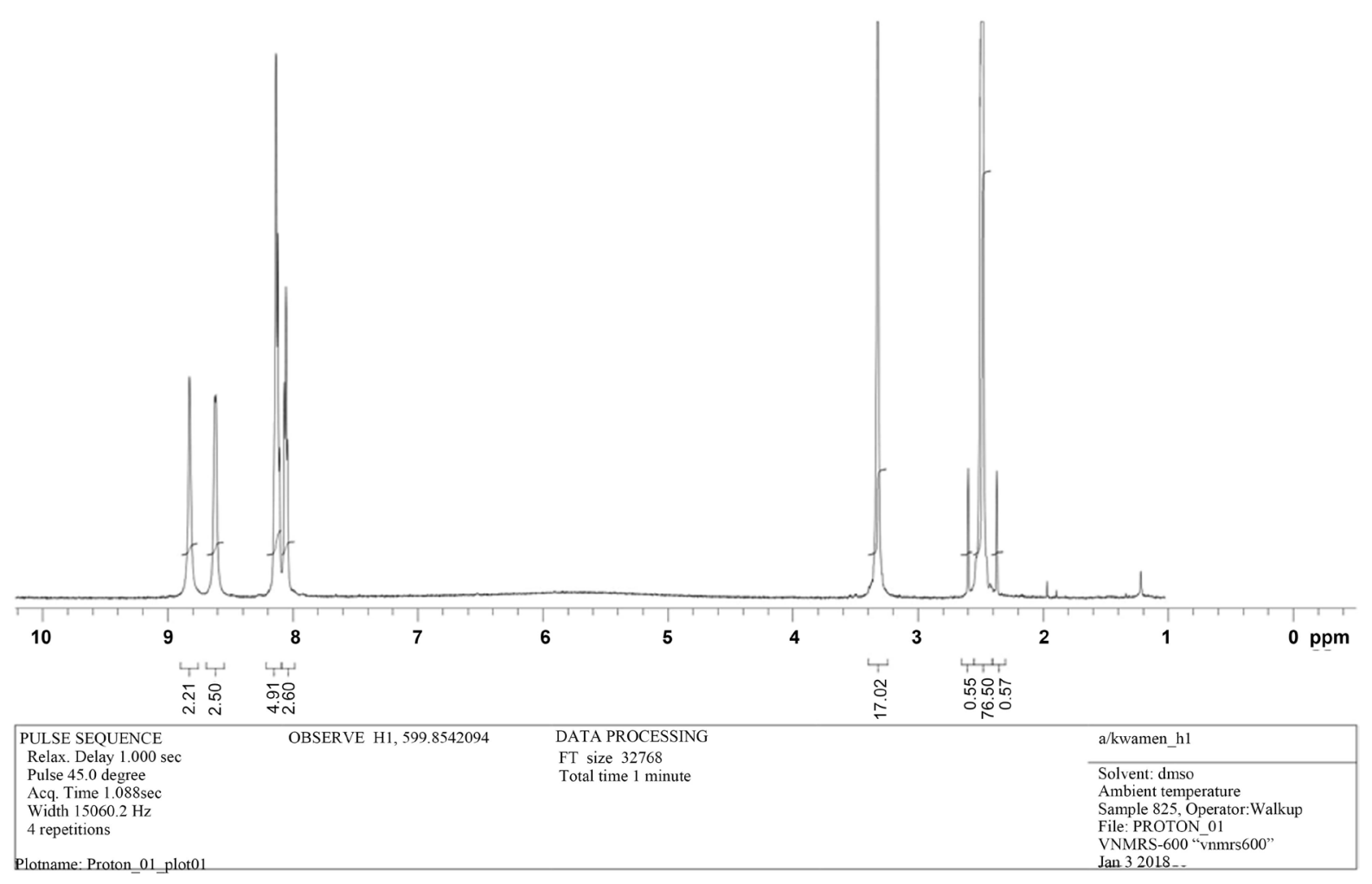

Figure 6. ${ }^{1} \mathrm{H}-\mathrm{NMR}$ spectrum of PHEO.

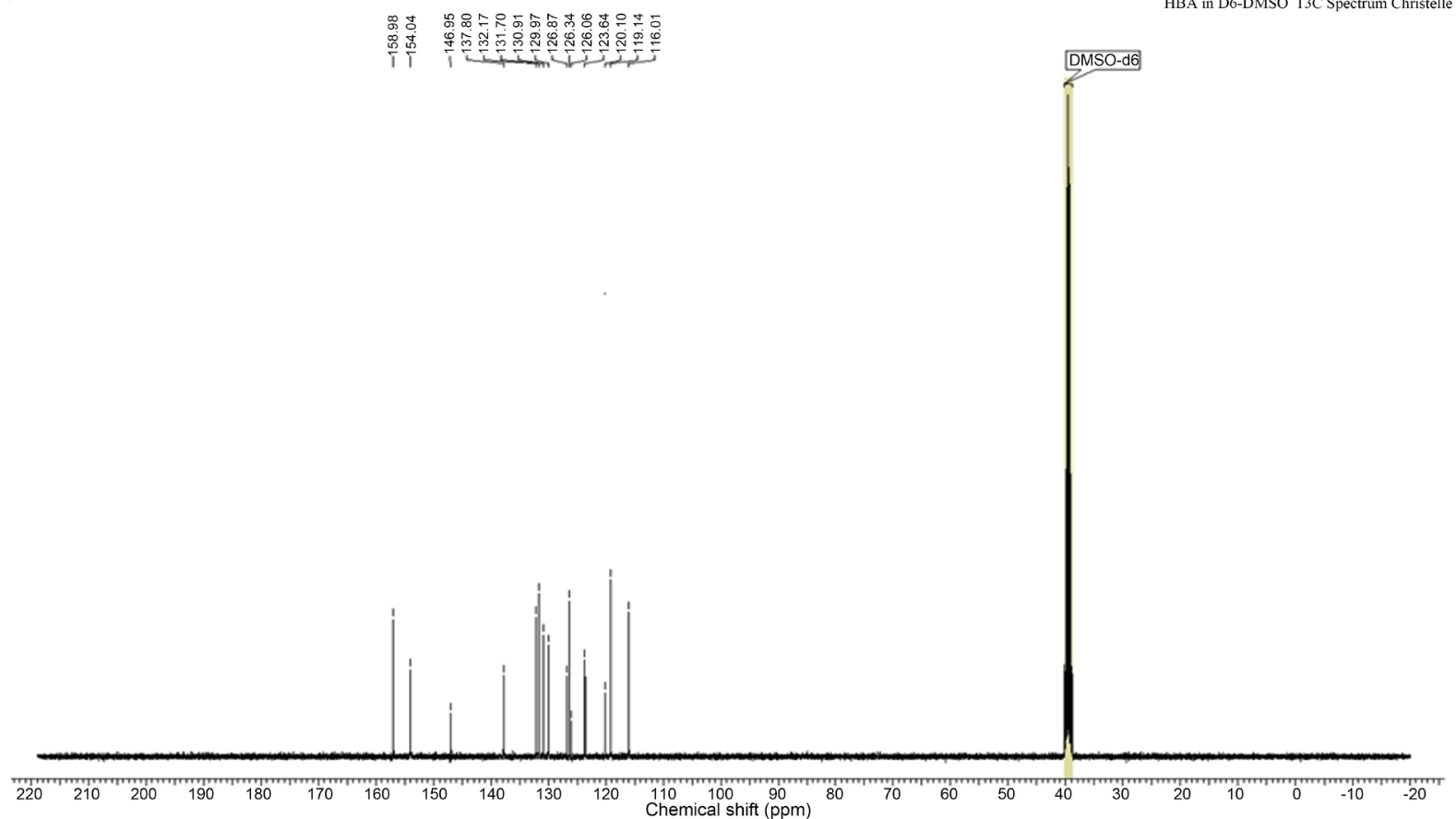

HBA in D6-DMSO 13C Spectrum Christelle

Figure 7. ${ }^{13} \mathrm{C}$ NMR spectrum of PHMP.

The ${ }^{13} \mathrm{C}$ NMR spectrum of PHEO (Figure 8) was recorded in deuterated DMSO as the solvent. The signals at 151.6, 135.9 and 134.2 were respectively assigned to carbons 1', 1 and 4 . 
Plotname: Proton_01_plot01

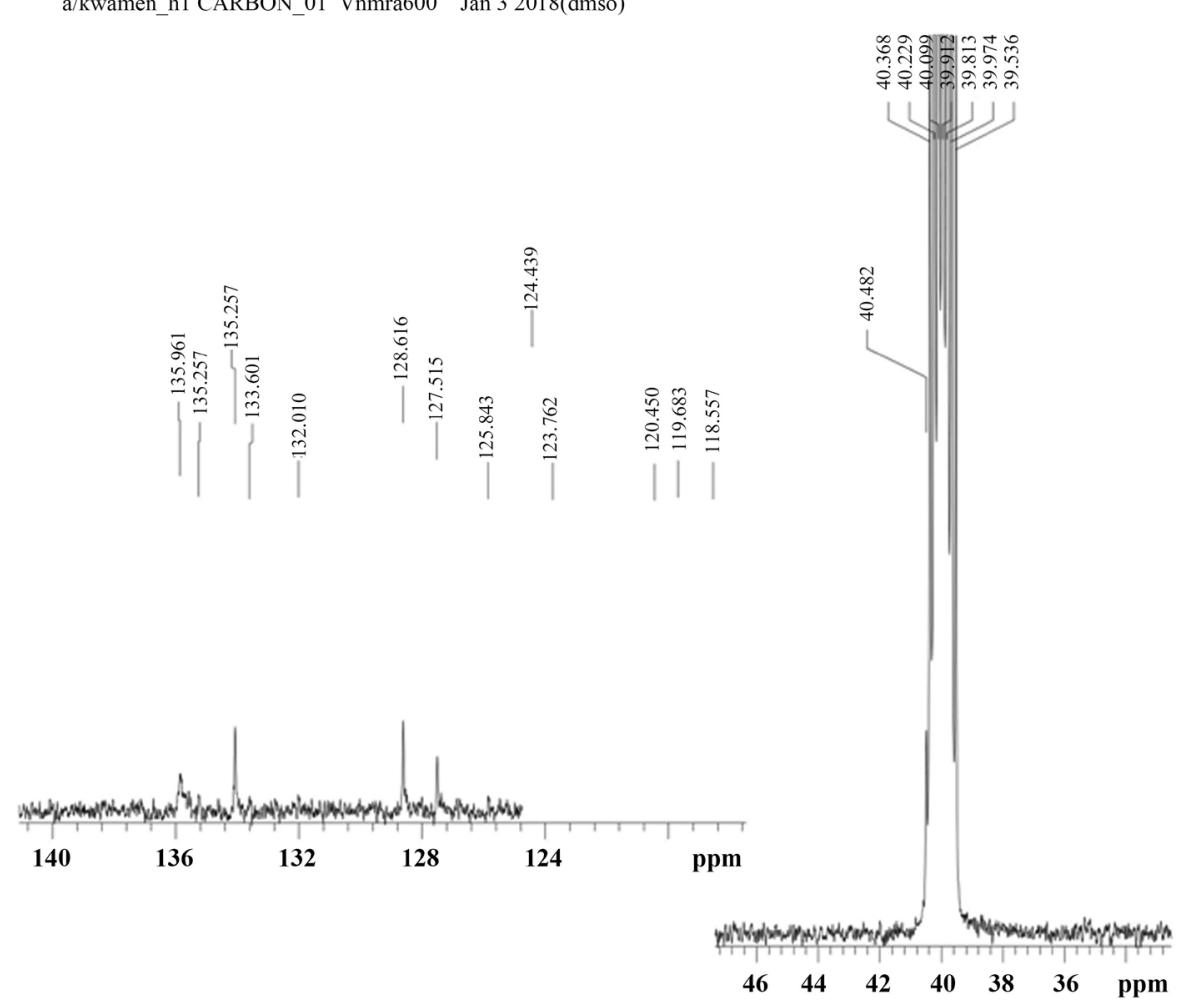

Figure $8 .{ }^{13} \mathrm{C}$ NMR Spectrum of PHEO.

\subsection{Anti-Plasmodial Activity}

PHEO and PHMP were tested for anti-plasmodial activity using the SYBR green I based fluorescence assay and the results are presented in Table 1. PHEO inhibited the growth of the malaria parasites with a percentage inhibition of $78.55 \%$, lower than the $80.41 \%$ obtained with the standard treatment of malaria, Artemisinin. Likewise, PHMP inhibited the growth of the malaria parasites with a percentage inhibition of $78.06 \%$, lower than the $80.41 \%$ obtained with the standard treatment of malaria, Artemisinin. Considering that their percentage inhibitions in the preliminary assay were less than 80\%, PHEO and PHMP were not considered for the Dose-Response studies.

\subsection{Antimicrobial Activity}

Antibacterial activities of PHEO and PHMP are recorded in Table 2. PHEO showed low activity only on one bacterial strain with MIC value of $250 \mu \mathrm{g} / \mathrm{ml}$ against Hemophyllus influenza ATCC49247. Antimicrobial activity of a compound is very interesting if the MIC is below $10 \mu \mathrm{g} / \mathrm{ml}$, interesting or moderate if $10<\mathrm{MIC} \leq 100 \mu \mathrm{g} / \mathrm{ml}$ and low if MIC > $100 \mu \mathrm{g} / \mathrm{ml}$ [15] [27]. Based on above-mentioned criteria, PHEO had low antimicrobial activity. PHMP was effective (interesting activity) against 4 bacterial strains out of 19 with MIC of 31.25 - $250 \mu \mathrm{g} / \mathrm{ml}$ against Hemophyllus influenza ATCC49247; Staphylococcus aureus NR46374; Staphylococcus aureus BAA 917 and Streptococcus pneumoniae 
Table 1. Antiplasmodial activity of synthetic compounds.

\begin{tabular}{ccc}
\hline Compound & \% Inhibition & $\mathrm{IC}_{50}(\mu \mathrm{g} / \mathrm{mL})$ \\
\hline PHEO & 78.55 & N.D. \\
PHMP & 78.06 & N.D. \\
ART & 80.41 & $18.18 \mathrm{nM}$ \\
CQ & N.D. & $449.3 \mathrm{nM}$ \\
\hline
\end{tabular}

$\mathrm{ART}=$ artemisinine; $\mathrm{CQ}=$ chloroquine; $\mathrm{N} . \mathrm{D} .=$ Not determined.

Table 2. Antibacterial activities of PHEO and PHMP.

\begin{tabular}{|c|c|c|c|}
\hline \multicolumn{4}{|c|}{ Antimicrobial activity (MIC in $\mu \mathrm{g} / \mathrm{mL}$ ) } \\
\hline Bacterial strains, Synthetic compounds & PHEO & PHMP & Amoxicilin \\
\hline Streptococcus pneumoniae (Klein) Chester, ATCC49619 & $>250$ & 250 & 0.5 \\
\hline Staphylococcus aureus BAA 917; & $>250$ & 125 & 8 \\
\hline Staphylococcus aureus subsp. aureus Rosenbach, ATCC 43300 & $>250$ & $>250$ & $>64$ \\
\hline Staphylococcus aureus $\mathrm{NR} 45003$ & $>250$ & $>250$ & $>64$ \\
\hline Staphylococcus aureus NR46003 & $>250$ & $>250$ & $>64$ \\
\hline Staphylococcus aureus CP7625 & $>250$ & $>250$ & 4 \\
\hline Shigellaflexineri NR518 & $>250$ & $>250$ & 2 \\
\hline Salmonella enterica subsp. enterica serovar Anatum, NR4294 & $>250$ & $>250$ & 16 \\
\hline $\begin{array}{l}\text { Salmonella enterica subsp. enterica serovar Muenchen, } \\
\text { NR4311 }\end{array}$ & $>250$ & $>250$ & 0.5 \\
\hline $\begin{array}{c}\text { Salmonella enterica subsp. enterica, strain A36 is serovar } \\
\text { Typhimurium, NR-13555 }\end{array}$ & $>250$ & $>250$ & 64 \\
\hline Pseudomonas aeruginosa NMC592 & $>250$ & $>250$ & 0.5 \\
\hline $\begin{array}{c}\text { Klebsiella pneumoniae subsp. pneumoniae (Schroeter) } \\
\text { Trevisan ATCC } 13883\end{array}$ & $>250$ & $>250$ & 2 \\
\hline $\begin{array}{c}\text { Klebsiellapneumoniaesubsp. pneumoniae (Schroeter) } \\
\text { Trevisan ATCC } 700603\end{array}$ & $>250$ & $>250$ & 4 \\
\hline KlebsiellapneumonaeNR41916 & $>250$ & $>250$ & 2 \\
\hline Escherishia coli ATCC25922 & $>250$ & $>250$ & 2 \\
\hline Escherishia coli ATCC 35218 & $>250$ & $>250$ & $>$ \\
\hline Enterococcus feacalis ATCC51219 & $>250$ & $>250$ & 4 \\
\hline Staphylococcus aureus NR46374 & $>250$ & 31.25 & 1 \\
\hline Hemophyllus influenza ATCC49247 & 250 & 31.25 & 0.5 \\
\hline
\end{tabular}

(Klein) Chester ATCC49619. However, the results achieved can serve as starting point for lead optimisation in order to generate more active lead compounds that can be developed into new antibacterial drugs.

\subsection{Antioxidant Activity}

\subsubsection{Ferric Reducing Powder and Lipid Peroxidation}

The effects of different compounds and vitamin $\mathrm{C}$ on reduction of ferric ions 
and peroxidation of lipids are presented in Table 3. In general PHEO and PHMP showed higher reducing activity on ferric ions than the reference compound vitamin $\mathrm{C}$. On lipid peroxidation, $\mathrm{PHEO}$ showed higher inhibition $(\mathrm{P}<$ $0.05)$ while PHMP showed lower inhibition $(\mathrm{P}<0.05)$ compared to vitamin $\mathrm{C}$.

\subsubsection{Catalase Activity}

The catalase activity in the presence of PHEO, PHMP and Vitamin C is depicted in Figure 9. Catalase activity showed concentration dependent effect in the presence of all compound. In general Vit $\mathrm{C}$ presented higher stimulatory effect on the enzyme activity than PHEO and PHMP. PHMP showed a lower effect on catalase activity.

\section{Conclusions}

PHEO and PHMP were synthesized from hydralazine hydrochloride and characterized by spectroscopic methods.

PHEO showed low anti-microbial activity only on one bacterial strain with MIC value of $250 \mu \mathrm{g} / \mathrm{ml}$ against Hemophyllus influenza ATCC49247. PHMP showed interesting activity against 4 bacterial strains out of 19 with MIC of 31.25 - $250 \mu \mathrm{g} / \mathrm{ml}$ against Hemophyllus influenza ATCC49247; Staphylococcus aureus NR46374; Staphylococcus aureus BAA 917 and Streptococcus pneumoniae (Klein) Chester ATCC49619.

For antioxidant activity, PHEO and PHMP showed higher reducing activity on ferric ions than the reference compound Vit $\mathrm{C}$ and on lipid peroxidation,

Table 3. Effects of compounds and Vit $\mathrm{C}$ on reduction of ferric ions and peroxidation of lipids.

\begin{tabular}{ccc}
\hline & Ferric reducing power & Lipid peroxidation \\
\cline { 2 - 3 } & $\mathrm{EC}_{50}(\mu \mathrm{g} / \mathrm{mL})$ & $\mathrm{IC}_{50}(\mu \mathrm{g} / \mathrm{mL})$ \\
\hline Vit C & $1.749 \pm 0.001$ & $1.45 \pm 0.01$ \\
PHEO & $1.348 \pm 0.047^{*}$ & $1.03 \pm 0.32^{*}$ \\
PHMP & $1.368 \pm 0.105^{*}$ & $2.59 \pm 0.19^{*}$ \\
\hline
\end{tabular}

${ }^{\star} \mathrm{P}<0.05$ compared to the reference Vit C, Student-Newman-Keuls test.
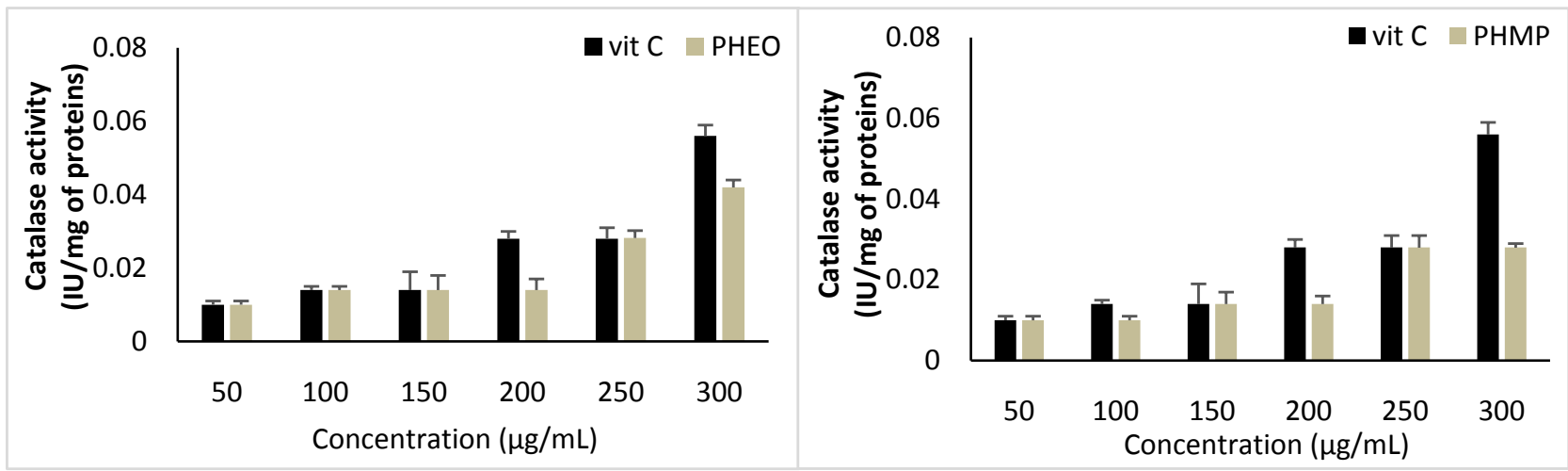

Figure 9. Effects of compounds and Vitamin C on catalase activity. 
PHEO and PHMP showed higher inhibition than Vit C. Catalase activity showed concentration dependent effect in the presence of all compounds. In general, Vit $C$ presented higher stimulatory effect on the enzyme activity than PHEO and PHMP. PHMP showed a lower effect on catalase activity.

PHEO and PHMP inhibited the growth of the malaria parasites with percentage inhibitions of $78.55 \%$ and $78.06 \%$ respectively; lower than the $80.41 \%$ obtained with the standard treatment of malaria, Artemisinin. Considering that their percentage inhibitions in the preliminary assay were less than $80 \%$, PHEO and PHMP were not considered for the Dose-Response studies.

The anti-microbial, anti-oxidant and anti-plasmodial activities of these compounds are reported for the first time and the results indicate that these novel ligands can be exploited as anti-microbial and anti-oxidant agents.

\section{Acknowledgements}

We are grateful to the Department of Chemistry, University of Buea for providing the necessary support to perform the experiments.

\section{Conflicts of Interest}

The authors declare no conflicts of interest regarding the publication of this paper.

\section{References}

[1] Sathe, B.S., Jaychandran, E., Jagtap, V.A. and Sreenivasa, G.M. (2011) Synthesis Characterization and Anti-Inflammatory Evaluation of New Fluorobenzothiazole Schiff's Bases. International Journal of Pharmaceutical Research and Development, 3, 164-169. https://doi.org/10.1155/2013/893512

[2] Sondhi, S.M., Singh, N., Kumar, A., Lozach, O. and Meijer, L. (2006) Synthesis, Anti-Inflammatory, Analgesic and Kinase (CDK-1, CDK-5 and GSK-3) Inhibition Activity Evaluation of Benzimidazole/Benzoxazole Derivatives and Some Schiffs Bases. Bioorganic and Medicinal Chemistry, 14, 3758-3765. https://doi.org/10.1016/j.bmc.2006.01.054

[3] Pandey, A., Dewangan, D., Verma, S., Mishra, A. and Dubey, R.D. (2011) Synthesis of Schiff Bases of 2-Amino-5-aryl-1,3,4-thiadiazole and Its Analgesic, Anti-Inflammatory, Anti-Bacterial and Anti-Tubercular Activity. International Journal of ChemTech Research, 3, 178-184. https://doi.org/10.1155/2012/145028

[4] Chandramouli, C., Shivanand, M.R., Nayanbhai, T.B., Bheemachari, B. and Udupi, R.H. (2012) Synthesis and Biological Screening of Certain New Triazole Schiff Bases and Their Derivatives Bearing Substituted Benzothiazole Moiety. Journal of Chemical and Pharmaceutical Research, 4, 1151-1159.

[5] Chinnasamy, R.P., Sundararajan, R. and Govindaraj, S. (2010) Synthesis, Characterization, and Analgesic Activity of Novel Schiff Base of Isatin Derivatives. Journal of Advanced Pharmaceutical Technology and Research, 1, 342-347. https://doi.org/10.4103/0110-5558.72428

[6] Venkatesh, P. (2011) Synthesis, Characterization and Antimicrobial Activity of Various Schiff Bases Complexes of $\mathrm{Zn}(\mathrm{II})$ and $\mathrm{Cu}(\mathrm{II})$ Ions. Asian Journal of Pharmaceutical and Health Sciences, 1, 8-11. 
https://doi.org/10.1016/j.rechem.2019.100006

[7] Chaubey, A.K. and Pandeya, S.N. (2012) Synthesis \& Anticonvulsant Activity (Chemo Shock) of Schiff and Mannich Bases of Isatin Derivatives with 2-Amino Pyridine (Mechanism of Action). International Journal of PharmTech Research, 4, 590-598. https://doi.org/10.11648/j.ajhc.20190502.12

[8] Miri, R., Razzaghi-asl, N. and Mohammadi, M.K. (2013) QM Study and Conformational Analysis of an Isatin Schiff Base as a Potential Cytotoxic Agent. Journal of Molecular Modeling, 19, 727-735. https://doi.org/10.1007/s00894-012-1586-x

[9] Avaji, P.G., Vinod Kumar, C.H., Patil, S.A., Shivananda, K.N. and Nagaraju, C. (2009) Synthesis, Spectral Characterization, In-Vitro Microbiological Evaluation and Cytotoxic Activities of Novel Macrocyclic Bishydrazone. European Journal of Medicinal Chemistry, 44, 3552-3559. https://doi.org/10.1016/j.ejmech.2009.03.032

[10] Venugopala, K.N. and Jayashree, B.S. (2003) Synthesis of Carboxamides of 2'-amino-4'-(6-bromo-3-coumarinyl) Thiazole as Analgesic and Antiinflammatory Agents. Indian Journal of Heterocyclic Chemistry, 12, 307-310.

[11] Mounika, K., Anupama, B., Pragathi, J. and Gyanakumari, C. (2010) Synthesis, Characterization and Biological Activity of a Schiff Base Derived from 3-Ethoxy Salicylaldehyde and 2-Amino Benzoic Acid and Its Transition Metal Complexes. Journal of Scientific Research, 2, 513-524. https://doi.org/10.3329/jsr.v2i3.4899

[12] Aboul-Fadl, T., Mohammed, F.A. and Hassan, E.A. (2003) Synthesis, Antitubercular Activity and Pharmacokinetic Studies of Some Schiff Bases Derived from 1-Alkylisatin and Isonicotinic Acid Hydrazide (INH). Archives of Pharmacal Research, 26, 778-784. https://doi.org/10.1007/BF02980020

[13] Chohan, Z.H., Praveen, M. and Ghaffar, A. (1997) Structural and Biological Behaviour of $\mathrm{Co}(\mathrm{II}), \mathrm{Cu}(\mathrm{II})$ and $\mathrm{Ni}(\mathrm{II})$ Metal Complexes of Some Amino Acid Derived Schiff-Bases. Metal-Based Drugs, 4, 267-272. https://doi.org/10.1155/MBD.1997.267

[14] Knobler, S.L., Lemon, S.M., Najafi, M. and Burroughs, T. (2003) The Resistance Phenomenon in Microbes and Infectious Disease Vectors: Implications for Human Health and Strategies for Containment: Workshop Summary. National Academies Press (US), Washington DC.

[15] Piddock, L.J.V. (2017) Understanding Drug Resistance Will Improve the Treatment of Bacterial Infections. Nature Reviews Microbiology, 15, 639. https://doi.org/10.1038/nrmicro.2017.121

[16] Kuete, V. (2010) Potential of Cameroonian Plants and Derived Products against Microbial Infections: A Review. Planta Medica, 76, 1479-1491.

https://doi.org/10.1055/s-0030-1250027

[17] Frith, K.A., Fogel, R., Goldring, J.P.D., Krause, R.G.E., Khati, M., Hoppe, H. and Limson, J.L. (2018) Towards Development of Aptamers That Specifically Bind to Lactate Dehydrogenase of Plasmodium falciparum through Epitopic Targeting. Malaria Journal, 17, 191. https://doi.org/10.1186/s12936-018-2336-Z

[18] Yeung, S. (2018) Malaria-Update on Antimalarial Resistance and Treatment Approaches. The Pediatric Infectious Disease Journal, 37, 367-369. https://doi.org/10.1097/INF.0000000000001887

[19] Gülçin, I., Oktay, M., Kıreçci, E. and Küfreviolu, I. (2003) Screening of Antioxidant and Antimicrobial Activities of Anise (Pimpellaanisum L.) Seed Extracts. Food Chemistry, 83, 371-382. https://doi.org/10.4103/epj.epj_44_18

[20] Yoshikawa, T. and Naito, Y. (2002) What Is Oxidative Stress? JMAJ, 45, 271-276.

[21] Arnous, A., Makris, D.P. and Kefalas, P. (2001) Effect of Principal Polyphenolic 
Components in Relation to Antioxidant Characteristics of Aged Red Wines. Journal of Agriculture and Food Chemistry, 49, 5736-5742. https://doi.org/10.1021/jf010827s

[22] Kamtekar, S., Keer, V. and Patil, V. (2014) Estimation of Phenolic Content, Flavonoid Content, Antioxidant and Alpha Amylase Inhibitory Activity of Marketed Polyherbal Formulation. Journal of Applied Pharmaceutical Sciences, 4, 61-65.

[23] Nilsson, U.A., Olsson, L.I., Carlin, G. and Bylund-Fellenius, A.C. (1989) Inhibition of Lipid Peroxidation by Spin Labels. Journal of Biological Chemistry, 264, 11131-11135.

[24] Misra, H.P. and Fridovich, I. (1972) The Generation of Superoxide Radical during the Autoxidation of Hemoglobin. Journal of Biological Chemistry, 247, 6960-6962.

[25] Yong, J.N., Majoumo-Mbe, F., Samje, M. and Nfor, E.N. (2016) Synthesis, Molecular Structure and Anti-Onchocercal Studies of 1-(Phthalazin-1-(2H)-one)[(Pyridin2-yl)ethylidene]hydrazone. International Journal of Organic Chemistry, 6, 77-84. https://doi.org/10.4236/ijoc.2016.61008

[26] Nfor, E.N., Husian, A., Majoumo-Mbe, F., Njah, N.N., Offiong, E.O. and Bourne, S.A. (2013) Synthesis, Crystal Structure and Antifungal Activity of Ni(II) Complex of a New Hydrazine Derived from Antihypertensive Drug Hydralazine Hydrochloride. Polyhedron, 63, 213-217. https://doi.org/10.1016/j.poly.2013.07.028

[27] Singh, N., Kaushik, N.K., Mohanakrishnan, D., Tiwari, S.K. and Sahal, D. (2015) Antiplasmodial Activity of Medicinal Plants from Chhotanagpur Plateau, Jharkhand, India. Journal of Ethnopharmacology, 165, 152-162.

https://doi.org/10.1016/j.jep.2015.02.038 